\title{
Editorial
}

\section{Calcium Score and Myocardial Spect: Do We Need Anything Else?}

\author{
Jean-Marc Foult \\ American Hospital of Paris, France \\ *Corresponding author: Jean-Marc Foult, American Hospital of Paris, France, Tel: +0146412900; \\ E-mail: dr.jmfoult@gmail.com
}

Received Date: 18 July 2018; Accepted Date: 24 July 2018; Published Date: 02 July 2018

Coronary Artery Calcium Score (CAC) is not a perfect tool. But it is simply the best available information for predicting the risk of acute coronary syndromes; CAC has been tested in numerous studies involving tens of thousand patients, which have iteratively shown its superior prognostic value over traditional risk factors, including age [1]. In fact, one could probably say that CAC is the age of your coronary arteries, rather than the age calculated from your date of birth.

Comparative studies of pathological data and CAC have shown a close relationship between the total volume (or mass) of coronary atheroma and CAC. This probably explains in part the high predictive value of CAC, which in fact reflects the amount of calcified but also non-calcified plaques. These studies indicate that for one gram of calcified plaque, there are 5 grams of non-calcified atheroma $[2,3]$.

Despite its good predictive value, CAC cannot reliably identify the presence of a significant coronary stenosis on an individual basis, although the probability of significant stenosis or ischemia statistically rises with CAC [4]. Therefore, as outlined in a recent editorial, [5] we believe that the association of CAC and myocardial SPECT is an adequate tool for patients with suspected ischemic heart disease.

Myocardial SPECT is a well-established test, the predictive value of which has been thoroughly documented over the past 30 years. The risk of events (acute myocardial infarction, sudden death or revascularization) increases with the amount of ischemic myocardium, from about $1 \%$ per year in patients with no ischemia, to more than $20 \%$ in those with $20 \%$ ischemic myocardium and more [5]. Interestingly, patients revascularized because they had $10 \%$ of ischemic myocardium or more, did better than those revascularized solely in view of the degree of coronary stenosis as determined by coronary angiography.

It has actually been repeatedly shown that revascularization based only on the appearance of coronary stenosis resulted in no prognosis improvement when compared to optimized medical therapy alone [6].
This is probably because assessing the severity of coronary stenosis from images obtained during coronary angiography, invasive or using Computed Tomography (CT), is a difficult challenge: the name of the game is to establish a difference between a 40 and a $60 \%$ stenosis. In a $3 \mathrm{~mm}$ diameter coronary artery, this represents a $0.6 \mathrm{~mm}$, distance, and in a $2 \mathrm{~mm}$ artery, we are left with $0.4 \mathrm{~mm}$, a distance which is far beyond the capacities of the human retinae, or of any currently available computerized system. Of note, the predictive value of both invasive coronary angiography and CTA for assessing the hemodynamic impact of a coronary stenosis, as determined by invasive Fractional Flow Reserve(FFR), is modest, in the range of 50 to $60 \%$ (50\% corresponds to a random result) [7].

Thus, it is difficult to precisely assess the functional severity of a coronary stenosis using currently available technologies for visualizing the coronary arteries. On the other hand, at maximal hypermia, coronary blood flow is almost unaffected by a $40 \%$ stenosis but is reduced by approximately $40 \%$ by a $60 \%$ stenosis, as established by landmark studies [8]. Imaging techniques providing information about myocardial perfusion are therefore intrinsically more adequate than " anatomical » techniques for establishing the significant nature of a coronary stenosis. Conversely, recent studies have established that revascularization based on FFR resulted in a better clinical outcome for patients, when compared to decisions based on coronary angiography alone [9].

The association of CAC and myocardial SPECT generates non-redundant and complementary diagnosis and prognosis data. As established in a recent study, [10] the risk rises for each category of CAC group (0, from 1 to 100 , from 101 to 200, etc....), but within each of these groups, the risk is higher in patients with myocardial ischemia than in those with a normal SPECT.

When performing CAC and myocardial SPECT, one gets to know about:

1. The physical capacity of the patient - when effort is used as a mean to elicit ischemia - an important marker of prognosis per se, 


\section{Ischemia (cf supra),}

3. Left ventricular function - which is routinely assessed using Gated-SPECT - and a major information too,

\section{4. $\quad$ CAC.}

Combined altogether, these 4 results provide a unique and comprehensive set of both diagnosis and prognosis information, which sets the ground for a rational management of each patient.

The association of CAC and myocardial SPECT has also several advantages from a practical standpoint. For instance, a zero-calcium score in a patient with borderline SPECT images helps to clarify the situation and reduces the number of SPECT false positive results [11]. On the other hand, a CAC $>1000$ in a patient with homogenous SPECT images may rise the possibility of multivessel disease, especially if the patient is symptomatic and/ or has a positive stress test; this may lead to invasive coronary angiography [12].

In a patient with a normal SPECT, CAC can be of great interest to manage risk factors. A zero CAC favors pharmacological abstention, although this obviously needs to be discussed on a individual patient basis. Conversely, a high CAC should lead to aggressive pharmacological and non-pharmacological management of risk factors, as well as close follow-up [13].

At the present time, the association of CAC and myocardial SPECT provides a unique spectrum of information which permits a rationale management of patients with suspected coronary artery disease. Further results using cameras with improved performances (CZT) [14] should be available in a near future future to provide even more evidence for assessing both anatomy and function in patients with suspected heart disease.

\section{References}

1. Budoff MJ, Gul KM (2008) Expert review on coronary calcium. Vasc Health Risk Manag 4: 315-24.

2. Agatston AS, Janowitz WR, Hildner FJ, Zusmer NR, Viamonte M Jr, et al. (1990) Quantification of coronary artery calcium using ultrafast computed tomography. J Am Coll Cardiol 15: 827-832.

3. Tam LM, Kim J, Blumenthal RS, Nasir K, Al-Mallah, et al. (2013) Absolute coronary artery calcium score is the best predictor of non-calcified plaque involvement in patients with low calcium scores (1-100). Atherosclerosis 230: 76-79.
4. Rozanski A, Berman DS (2018) The Synergistic Use of Coronary Artery Calcium Imaging and Noninvasive Myocardial Perfusion Imaging for Detecting Subclinical Atherosclerosis and Myocardial Ischemia. Curr Cardiol Rep 20: 59.

5. Hachamovitch R, Hayes SW, Friedman JD, Cohen I, Berman DS (2003) Comparison of the short-term survival benefit associated with revascularization compared with medical therapy in patients with no prior coronary artery disease undergoing stress myocardial perfusion single photon emission computed tomography. Circulation 107: 2900-2907.

6. Katritsis DG, loannidis JP (2005) Percutaneous coronary intervention versus conservative therapy in nonacute coronary artery disease: a meta-analysis. Circulation 111: 2906-2912.

7. Budoff MJ, Nakazato R, Mancini GJ, Gransar H, Leipsic, et al. (2016) CT angiography for the prediction of hemodynamic significance in intermediate and severe lesions: head-to-head comparison with quantitative coronary angiography using fractional flow reserve as the reference standard. JACC Cardiovascular Imaging 9: 559-564.

8. Gould KL, Kirkeeide RL, Buchi M (1990) Coronary flow reserve as a physiologic measure of stenosis severity. J Am Coll Cardiol 15: 459-474.

9. Tonino PA, De Bruyne B, Pijls NH, Siebert U, Ikeno, et al. (2009) Fractional flow reserve versus angiography for guiding percutaneous coronary intervention. N Engl J Med. 360: 213-224.

10. Engbers, E. M., Timmer, J. R., Ottervanger, J. P., Mouden, M., Knollema, et al. (2016). Impact of gender on the prognostic value of coronary artery calcium in symptomatic patients with normal single-photon emission computed tomography myocardial perfusion. American J cardiol 118: 1611-1615.

11. Mouden M, Ottervanger JP, Timmer JR, Reiffers S, Oostdijk, et al. (2014) The influence of coronary calcium score on the interpretation of myocardial perfusion imaging. J Nucl Cardiol 21: 368-374.

12. Engbers EM, Timmer JR, Mouden M, Knollema S, Jager PL, et al. (2017) Changes in cardiovascular medication after coronary artery calcium scanning and normal single photon emission computed tomography myocardial perfusion imaging in symptomatic patients. Am Heart J: 186: 56-62.

13. Yokota S, Mouden M, Ottervanger JP, Engbers E, et al. (2017) Coronary calcium score influences referral for invasive coronary angiography after normal myocardial perfusion SPECT. J Nucl Cardiol pp. 1-11.

14. Mouden M, Ottervanger JP, Knollema S, Timmer JR, Reiffers S, et al. (2014). Myocardial perfusion imaging with a cadmium zinc telluride-based gamma camera versus invasive fractional flow reserve. Eur J Nucl Med Mol Imaging 41: 956-962.

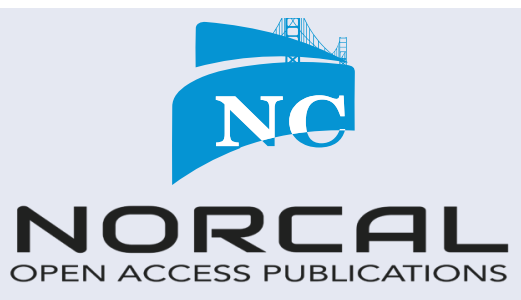

submit your manuscripts at www. norcaloa.com 